\title{
El cristianismo y la guerra de los humanismos en los Estados Unidos ${ }^{1}$
}

Walter Redmond Huston-Tillotson University wbredmond.wr@gmail.com

We express these limits... by saying the parties are behind a veil of ignorance. John Rawls ${ }^{2}$

La guerra de los humanismos

En el escenario estadounidense son muy populares las palabras bonitas: libertad y opción, respeto y tolerancia, apertura y acogida, «inclusividad», pluralismo, diversidad, multiculturalismo; transigencia y concesión, compasión y sensibilidad, imparcialidad y antidiscriminación; justicia, derechos e igualdad bajo la ley; procesos democráticos; libertad de religión y de conciencia. Sin embargo, la realidad no es tan

\footnotetext{
1 Conferencia magistral, 26 de octubre del III Coloquio Internacional Humanismo en la Universidad Pública: Las Humanidades y la Formación Humanista, Universidad Autónoma de Aguascalientes, 26-30 de octubre de 2009.

2 «Expresamos esos límites de información en metáfora diciendo que los involucrados quedan tras un velo de ignorancia», Rawls (2001).
} 
bonita, pues se ha librado una guerra a ultranza entre dos humanismos: dos cosmovisiones con sendas antropologías y éticas. Uno de los humanismos está ganando; el otro, cada vez más acosado, está perdiendo. Llamaré a los humanistas triunfantes los «de arriba» y a los humanistas que éstos quieren derrotar los «de abajo». Hay, pues, un humanismo de arriba y un humanismo de abajo, y la lucha entre ellos es encarnizada.

Quisiera plantear una cuestión ética en torno a estos dos humanismos en conflicto. «Plantear» digo, y las soluciones se las dejo a ustedes, los profesores universitarios. Les pediré una teoría. A propósito, el humanismo cristiano tradicional está abajo.

La guerra de los humanismos es compleja y me ceñiré a los «extremos» de la polarización. Todos los sectores de la sociedad están involucrados: gente común y corriente, legisladores, jueces, comentaristas mediáticos, maestros y profesores universitarios -los cristianos (la Iglesia católica también está escindida en humanistas de arriba y humanistas de abajo).

La cuestión ética que plantearé es crucial, decisiva, porque lo que está en juego es la misma libertad, ese precioso logro que la nación estadounidense presume haber afianzado para siempre y promover en el resto del mundo. En realidad, el mismo enfrentamiento aqueja otros países y, en algunos, el triunfo del humanismo de arriba está más avanzado.

\section{Límites de la discusión}

Quiero comenzar despejando la discusión. Es decir, quiero eliminar tres cosas que complicarían nuestra reflexión y harían imposible una solución sensata. La primera son las leyes, la segunda son las cuestiones éticas primarias y la tercera es 
la sociología o psicología de los pareceres. Permítanme explicar estas restricciones.

El primer punto es evidente. Hablaremos de la ética, la moralidad, no de la jurisprudencia; nos interesa la justicia, no las leyes. Pues la ética juzga las leyes; las leyes no juzgan la ética. Hay leyes injustas y es la ética la que dice que lo son. La Corte Suprema de los EEUU decretó, en 1857, que a los amos no se les podía arrebatar a sus esclavos, por ser éstos chattel (propiedad privada $)^{3}$. Ni hay por qué pensar que algunas leyes actuales, ni algunos fallos de los jueces, no sean tan funestos.

\section{Los niveles de la ética}

El segundo tema de que no haremos caso son las cuestiones morales primarias, para concentrarnos en el aspecto metaético. Pues en la ética hay planteamientos primarios y metaéticos. Aquí cambio un poco el sentido acostumbrado de «metaética». La palabra suele contrastarse con la «ética normativa», pero la metaética en mi sentido también es normativa. Ambos niveles, el primero y el metaético, por ser normativos, dicen lo que hay que hacer y evitar.

Les contaré una anécdota para explicar la diferencia entre los niveles primario y metaético de la ética. Una vez asistí al «Referat» que presentó un estudiante de posgrado de filosofía en una universidad europea. Su tema fue la moralidad del lenguaje inclusivo: preguntaba si era inmoral negarse a usarlo. Un ejemplo del lenguaje inclusivo en español son las expresiones desdobladas: sería de rigor escribir alumno/a (barra oblicua) o alumn@ (arroba) para evitar el uso machista del género masculino. En alemán habría que decir Studierende en

No al menos sin los justos procedimientos; la decisión: Dred Scott versus Sandford. 
vez de Student y Studentin (alumno y alumna). En eevu son capaces de llevarte ante el tribunal si dices niggardly (tacaño), pues la palabra suena a cierto epíteto racista (aunque no hay relación etimológica).

Bueno, mientras el alumno presentaba varios argumentos a favor y en contra se me ocurría una pregunta, pero el rector (que estaba presente) se me adelantó. El rector (que es un filósofo eminente) hizo esta pregunta al estudiante:

Mire, joven, el editor de [aquí nombró cierta revista alemana de filosofía] me acaba de decir que no publicará el artículo que le mandé a menos que le meta lenguaje inclusivo. Pero yo creo que el lenguaje inclusivo se ha convertido en una manía. Lo que yo pregunto es (aparte de la moralidad de no usar el lenguaje inclusivo), ¿ese editor tenía el derecho de rechazar mi artículo sólo porque yo no acepto su dogma sobre el lenguaje inclusivo?

Claro, el estudiante se quedó boquiabierto, porque se le escapó totalmente la cuestión metaética: ¿no es abuso de poder imponer el lenguaje inclusivo? ¿Tiene el editor derecho a exigir que un autor rinda homenaje público a lo que considera como un moralismo zonzo?

Voy a esto: el lenguaje inclusivo es cuestión abierta, discutible. Muchos creen que el lenguaje inclusivo ya ha ido demasiado lejos, o bien les inquietan las ideologías detrás de él ${ }^{4}$. Hay que preguntar, pues, en el nivel metaético: la imposición del lenguaje inclusivo, ¿no es abuso de poder? He aquí el patrón de ambas cuestiones:

James Q. Wilson (1993) explica en una nota al lector por qué usa man y his en el sentido genérico (contra el lenguaje inclusivo): aunque esté de moda, dice, los rodeos que se usan para evitar el estilo no-inclusivo (gender-based writing) son «torpes y sosos». 
Nivel metaético ¿Es lícito castigar a los que no usan el lenguaje inclusivo?

Nivel primario ¿Es malo desdeñar el lenguaje inclusivo?

Por supuesto, la argumentación en los dos niveles será distinta. El editor tiene que mostrar por qué «es malo no usar el lenguaje inclusivo»; podría decir, por ejemplo: «porque discrimina a las mujeres». Pero también debería decir, en el nivel metaético, por qué tiene derecho a rechazar a los autores que prefieren no usar el lenguaje inclusivo; por ejemplo, podría decir: «el error no tiene derechos».

Ahora bien, la insistencia en el lenguaje inclusivo es una típica causa del humanismo de arriba. Y la cuestión ética crucial que mencioné (la cual a menudo pasa desapercibida) es metaética, y atañe a la negación de la libertad. Claro, en los EEUU hay muchas cuestiones éticas primarias que son mucho más candentes que el lenguaje inclusivo. Abstengámonos, sin embargo, de discutir el aspecto primario de ellas, y planteemos más bien la cuestión metaética general: ¿el poder de arriba tiene el derecho de imponer su voluntad?

\section{La moda y los pareceres}

Hablé de las leyes porque quería separarlas de la discusión ética, y hablé de la metaética porque es metaético el problema del abuso de poder que queremos enfocar. La tercera cosa que quiero eliminar de nuestra discusión es el prestigio social que corresponde a los pareceres de arriba. Es una cuestión de psicología, de sociología. Pues existe cierto clasismo epistémico en los EEUU. La gente de arriba se aglutina alrededor de 
sus convicciones de arriba; la gente de abajo se arracima en torno a actitudes que contradicen las de arriba ${ }^{5}$.

Pero hay una diferencia importante: los puntos de vista de arriba son de prestigio, están de moda; son, por así decirlo, oficialmente correctos. Los opinadores de arriba son respetables, serios, sofisticados. El editor de la revista está arriba porque su apoyo al lenguaje inclusivo es una creencia respetada de arriba; y mi amigo, el autor del artículo (pese a ser un filósofo de renombre mundial) queda, en lo concerniente al lenguaje inclusivo, abajo. En cambio, en EEUU se considera que las ideas de los de abajo son pasadas de moda, desacreditadas, anticuadas, retrógradas, equivocadas, ingenuas, plebeyas.

Además, los proyectos morales de arriba pertenecen al porvenir, se supone que han de prevalecer, superarán las tercas resistencias de los de abajo (es importante insistir en este espíritu escatológico del humanismo de arriba). Los de arriba toman la iniciativa, desean cambiar el status quo que ven como deficiente. $\mathrm{Y}$ los cambios que proponen sorprenden a los de abajo, quienes, desprevenidos, tardan en darse cuenta y responder. Antes, el criterio para que un artículo fuera aceptado en aquella revista alemana era su contenido filosófico; ahora los autores también tienen que acatar una doctrina contra la que podrían ofrecer argumentos razonables.

Este clasismo intelectual no tiene nada que ver con el estado social de los opinadores, con sus ingresos, con su nivel de escolarización. Nadie está más arriba en los EEUU -desde el ángulo de los de arriba- que las famosas «minorías». Tam-

No todas las cuestiones se dividen nítidamente. Si hubiera, digamos, cuatro asuntos discutidos, un partidario sostendría al menos tres. También hay personas (relativamente pocas) que están «a horcajadas», con un pie arriba y el otro abajo (ver Redmond 2001 y 1998). 
bién existe cierta movilidad epistémica hacia arriba, una especie de arribismo intelectual. Los de abajo suben; los de arriba raras veces bajan. La presión social para llegar arriba es casi irresistible.

Hay fanáticos por ambos lados. Los de arriba presumen de brights (brillantes) ${ }^{6}, \mathrm{y}$, porque los de abajo se atreven a resistir sus proyectos, los tildan de bufones ignorantes y oscurantistas, no sólo atrasados sino retrasados mentales ${ }^{7}$. Los de abajo califican a los de arriba de arrogantes farsantes, opresores fascistas. Como dice la canción de José Alfredo Jiménez Tú y las nubes:

yo pa'arriba volteo muy poco

tú pa' abajo no sabes mirar.

Toda esta caracterización, por supuesto, lisonjea a los humanistas de arriba, pero no crean que sólo ellos la aceptan, pues los de abajo también saben muy bien -con gran disgusto suyo- que están abajo. Mi amigo alemán se sintió mortificado cuando el editor, en vez de discutirlo, simplemente le impuso una decisión por sus pistolas. Lo que lo fastidia más que nada es que el editor no tenga dudas -no duda de que tenga el derecho de usar la fuerza; no argumenta, ni plantea la cuestión metaética.

Ahora bien, precisamente por el mismo prestigio y el poder de la gente de arriba, es menester recalcar que estos prejuicios epistémicos no tienen nada que ver con la verdad ni con la conveniencia o factibilidad de sus creencias. No hay por qué pensar que el discurso de arriba sea más racional que

Paul Geisert, promotor del «naturalismo».

British Association for Adoption and Fostering, Daily Mail, 14 de mayo. 
el de abajo. En efecto, se acusa frecuentemente a los de arriba de platicar en comunicados scripted (ya hechos, cuidadosamente ensayados), y de usar una «neolengua» orwelliana, tipo 1984. Por ejemplo, los legisladores de arriba querían sacar una ley que llamaban «de libertad de conciencia» (FOCA), la cual habría obligado a los ciudadanos a actuar contra su conciencia, y lo que llaman una «doctrina de la imparcialidad» (fairness doctrine) tendría el efecto de desvirtuar a los comentadores de abajo en la radio AM.

En resumen, ciertas personas, por abrigar ciertas creencias prestigiosas, pertenecen a una clase epistémica alta, acreditada -y cada vez más potente; y este hecho lo reconocen, para su fastidio, también los otros, los de abajo:

Opinadores prestigiosos y poderosos

Opinadores desacreditados

Cristianos de arriba y de abajo

Dije que en los EEUU el humanismo cristiano tradicional está abajo y el humanismo de arriba viene adquiriendo cada vez más poder. En realidad, el «humanismo» generalmente se entiende como secular: ateo o al menos agnóstico. Con todo, muchos cristianos están arriba; un poco menos de la mitad de los católicos norteamericanos (a juzgar por la votación reciente) están arriba. Y existe el mismo arribismo epistémico: la tendencia de las denominaciones protestantes históricas es subir, y la subida, que exige el abandono de antiguas tradiciones morales, ha producido una polarización sumamente 
contenciosa ${ }^{8}$. Lo que divide a los cristianos es lo que divide a los norteamericanos en general: una serie de cuestiones humanísticas en torno al matrimonio y a la familia: la eutanasia y el aborto, la homosexualidad, la investigación embrionaria. Los cristianos de arriba quieren estar en misa y repicando a la vez: aceptan el credo moral de arriba pero se aferran a varios artículos reconfortantes del credo religioso (como la existencia de Dios o la inmortalidad del alma). Existe también un odium theologicum entre los teólogos católicos, pues los hay de arriba y los hay de abajo (el Papa está abajo).

\section{La historia}

Echemos un vistazo a la diferencia entre los dos credos humanistas, de arriba y de abajo, desde su historia. El término «humanismo» se usó primero en el Renacimiento, el movimiento filológico y artístico que ensalzaba las letras grecorromanas ${ }^{9}$. El enemigo de los renacentistas no era la religión, menos aún el cristianismo (hasta los papas contribuían al movimiento), sino la latinidad de la edad que estaba «en medio» de los autores clásicos que estimaban y ellos, los renacentistas.

En realidad, el humanismo tardó en sacudirse la religión. Incluso en la Ilustración, los ingleses tendían más bien al deísmo, los franceses pintaban la Razón (con mayúscula) como diosa y los alemanes retenían una concepción casi mística del

La escisión en la Iglesia anglicana ha sido tan profunda que entre 20 y 30 obispos anglicanos, con muchos sacerdotes y laicos, piden su ingreso en la Iglesia católica, insatisfechos con las innovaciones que sus correligionarios de arriba les han impuesto. Y el martes 20 (octubre, 2009), el Vaticano aceptó su petición. El anuncio, a propósito, fue revelado en una «rueda de prensa relámpago» para adelantarse a los medios de comunicación y evitar así sus interpretaciones malintencionadas, tan frecuentes últimamente. Zenith, 2009-10-20.

El evento iniciador fue la huída de los intelectuales de Bizancio a Italia cuando la ciudad cayó ante los turcos en 1453. Guillaume Tardif acuñó la palabra «humanismo» en 1475. 
mundo. En el siglo xIx, el filósofo Émile Comte fundó la Religión atea de la Humanidad (le vrai Grand' Être) con sus oraciones, himnos, sacramentos y un calendario litúrgico de sus santos -un «catolicismo sin cristianismo». La Religión de la Humanidad se fundó en Inglaterra (1878), en Nueva York (1869) y en el Brasil (1881) -existe todavía A Igreja Positivista do Brasil, que recomienda que sus feligreses hagan un hajj no a Roma sino a París ${ }^{10}$. En Francia, un segundo Comte acaba de sacar un manualito de espiritualidad atea ${ }^{11}$. En el siglo XIX, Julian Huxley predijo que el humanismo sería la última religión del mundo, y en efecto, la Corte Suprema de los EEUU llamó al humanismo una «religión» en $1961^{12}$.

Incluso la filosofía tardó en perder la fe. Nietzsche acusó a Hegel de ser un teólogo disfrazado de filósofo, pero Nietzsche mismo (que como tantos otros filósofos alemanes comenzó su carrera estudiando teología) confesó: Sein bin ich (soy suyo), hablando de su unbekannter Gott (dios desconocido), quien luego, infelizmente, falleció. Ahora se acusa al filósofo Lévinas de ser «criptoteólogo» por su devoción al Autrui (el Otro); callamos el Sein (el Ser) que Heidegger exaltó por encima del humanismo ${ }^{13}$. La famosa doctrina del eterno retorno de Nietzsche es una secularización y revela su nostalgia del č $\sigma \alpha \alpha \tau o v$ cristiano.

\section{La utopía atea}

Pero es efectivamente en la esperanza escatológica donde le ha sido difícil al humanismo desprenderse de la religión. Francis Bacon veía una nueva fe y esperanza en el progreso sin

Fundada en 1881 en el «mes de César»; ver www.igresjapositivistabrasil.org.br.

Comte-Sponville, A. (2006) L'esprit de l'atheisme. París: Albin Michel.

El fallo de Torcaso vs. Watkins.

Ver Wolin, 2006. Ver también: Heidegger, 1976, y Redmond, 2009. 
límites, don de la ciencia. Marx creía en una sociedad justa venidera. Y para su discípulo Ernst Bloch (llamado «el papa rojo» por piratear la Biblia para sacar la esperanza), el telos (meta, fin) de la historia es la «utopía del reino de la libertad», un «topos (lugar) en forma cristiana» -el «hogar de la identidad», el «porvenir absoluto», el «reino del cielo», la «bienaventuranza» ${ }^{14}$. Claro, todo esto pasará «en la tierra», no en el cielo. Bloch, sin embargo, barrunta: ¿quién sabe? ¿No vendrá al encuentro (entgegenkommen) de la actividad humana algún «ens perfectissimum» (ser más perfecto), un «summum bonum» (bien supremo)? -se sospecha que se trata de alguna doctrina clandestina de la «gracia». Bloch termina su libro Ateísmo en el cristianismo preguntando: «después de las disonancias, el último acorde suena bello - ¿quizás todavía más bello?» ${ }^{15}$, Bloch está repicando -no sé si está en misa.

El humanismo secular se cuajó en el siglo XIX, alrededor de una euforia meliorista. Para Hegel la realidad se está poniendo siempre más racional (lo mejor había llegado y era Hegel mismo). Marx creyó que la historia estaba progresando, y Darwin mostró que la misma naturaleza está mejorando. En efecto, después de la publicación del Origin of Species en 1859 el humanismo ateo creció exponencialmente -y comenzó a organizarse. No sólo se extendió la religión positivista, también se fundó la Unión Ética en Inglaterra en 1896; en EEUU salió el Manifiesto Humanista en 1933 (actualizado en 1973) y se estableció la Sociedad Humanista en 1949. Y por supuesto, la proscripción que se hace de Dios en la utopía secularizada de los movimientos socialistas ayudó enormemente a la causa del humanismo ateo.

Bloch, 1957; 1493.

En el original alemán: Der letzte Akkord klingt nach den Dissonanzen schön-vielleicht noch schöner? (Bloch, 1968). 
El optimismo secular se entibió algo en la primera mitad del siglo $x x$, cuando murieron en el combate sesenta millones de personas. Aldous Huxley publicó su Brave New World (Nuevo Mundo Feliz) en 1932 y en 1949 George Orwell su novela 1984. Las películas del futuro ya no pintan utopías, sino devastación atómica, el ébola, Manhattan convertido en calabozo, dominación por androides malvados. Pero siempre queda una pizca de esperanza: nuevos Adanes y Evas surgen de los escombros humeantes, y hasta el mismo Terminator llega a ser buenito; sin embargo, los ateos en muchas partes ahora salen del clóset y pasan al ataque. En los autobuses aparecen slogans como «Probablemente no existe Dios; deja pues de preocuparte y disfruta la vida». Muchos libros acometen contra la religión, aconsejando la «ateología». Incluso ha irrumpido la iconoclastia otra vez: la destrucción de los íconos religiosos, pues los policías culturales de arriba despojan las aulas y espacios comunes de los símbolos cristianos, «para garantizar», dicen, «el respeto al derecho de la libertad religiosa» (otro ejemplo de la neolengua orwelliana). Los cristianos se sienten cada vez más reducidos cuando quieren vivir y proclamar su religión, pero sí hay libertad para ridiculizarla y proscribirla.

\section{Habermas y las contraculturas}

En efecto, el humanismo de abajo en los EEuU ha sido hostigado cada vez más, sobre todo a partir de la revolución cultural alrededor de 1970, con una serie de medidas; con nuevas leyes o, cuando éstas no salen, por las interpretaciones de los «jueces activistas» (así la Iglesia católica ha sido excluida de varios servicios sociales, como el de la adopción); con el control mediático: las cadenas de televisión ( $\mathrm{ABC}, \mathrm{CBS}, \mathrm{NBC})$ es- 
tán arriba, así como los periódicos y revistas «importantes»; por resueltas organizaciones de arriba bien financiadas, como Planned Parenthood y la American Civil Liberties Union -otros ejemplos de la neolengua orwelliana: Planned Parenthood («el tener hijos») es la principal proveedora de abortos del país. $Y$ es sobre todo la escolarización pública y la formación universitaria lo que acosa el humanismo cristiano de abajo.

Los de abajo defienden su cultura lo mejor que pueden, formando una resistencia (algunos dicen un «underground»). La comunicación ha sido un problema, dado el antagonismo de los medios y de las escuelas; la excepción es la radio AM, que los de arriba no han podido controlar hasta el momento. Los de abajo establecen redes de escuelas hogareñas (home schooling) para esquivar el adoctrinamiento de la educación pública y proteger a sus hijos de los agresivos educadores, deseosos de impartir sus «valores» (y no las destrezas y habilidades que los niños necesitan $)^{16}$.

Los católicos de abajo también han formado comunidades de familias que educan a sus hijos en casa, y han fundado nuevas universidades o programas de estudios católicos para contrarrestar el impacto de las universidades católicas que se secularizaron mayoritariamente en los años sesenta y ahora se encuentran sólidamente arriba.

Es interesante que el filósofo alemán Jürgen Habermas tuviera mucha esperanza en lo que llamaba los «movimientos contraculturales» -todos de arriba, claro-, pues creyó que

Se reconoce el problema cuando el estado separa a los hijos de sus padres: ejemplo de esto es la canción cantada por la niña de seis años, Kang Wenjie («Cabellitos Rubios») mientras bailaba la «danza de la lealtad» durante la revolución Cultural de 1968: «Por más íntima que sea nuestra relación con nuestros papás, nunca será tan íntima como lo es con Mao» (Smithsonian, mayo, 2009, 10-12), y la obra de Berthold Brecht, «El Soplón» (Der Spitzel, en Furcht und Elend des Dritten Reich). 
conducirían a una «sociedad libre» exenta de discordia. En realidad ha ocurrido lo contrario en los EeUU: estos movimientos de arriba, a medida que consiguen más poder, reprimen a los humanistas que disienten de sus objetivos. El resultado es la discordia más alarmante que jamás haya visto en mi país. Tales movimientos de arriba dan la impresión de desear, no libertad, sino la Gleichschaltung (la supresión por los nazis de toda oposición en 1933), y la subcultura de Habermas ya no está «sub» nada (bajo nada), sino que está reinando desde arriba. Ahora la verdadera subcultura la forman los humanistas de abajo, quienes saben que viven no en una «sociedad libre» tipo Habermas, sino en lo que se ha llamado un totalitarismo blando.

Y como de costumbre, los norteamericanos de arriba exportan -a África, por ejemplo- su humanismo, lo que se ha llamado sus «desechos tóxicos espirituales».

\section{La libertad de conciencia}

Consideremos ahora la cuestión metaética en relación con la guerra de los humanismos. Claro, decir que los poderosos tienen el derecho de imponer su voluntad cultural es una posición metaética de arriba: negar que puedan usar su poder así es la posición de abajo. A pesar de sus diferencias, las muchas contenciosas áreas primarias entrañan el mismo problema metaético: la libertad de conciencia, pues está en el centro de la discusión la objeción de conciencia acerca de si los de abajo tienen el derecho de no ser castigados por negarse a participar en los proyectos morales de arriba. La misma rúbrica «objeción de conciencia» muestra hasta qué punto el humanismo cristiano está abajo y a la defensiva: los cristianos de abajo hacen frente a 
situaciones que amagan quitar su libertad o de hecho ya la han quitado ${ }^{17}$.

Tomemos el aborto como ejemplo, tal vez el área más preocupante en este momento ${ }^{18}$. El apoyo al aborto es una convicción de arriba. Los de abajo temen que el poder de arriba los obligue a apoyar el aborto, que les resulta repugnante. Ahora bien, es importante, para no involucrarnos en pleitos inútiles, que pasemos por alto la cuestión primaria (¿es lícito el aborto?) y hagamos la pregunta metaética: ¿el poder de arriba tiene el derecho de castigar a los de abajo que rehúsen intervenir en el aborto?

En Norteamérica y Europa son de hecho frecuentes los casos en los que los médicos, farmacéuticos y enfermeros que se niegan a tomar parte en abortos son despedidos. En EEUU, la creciente tendencia a definir el aborto y la eutanasia como prácticas «estándares» amenaza de varias maneras a los hospitales católicos y al personal de asistencia. Si los médicos de abajo no siguen el «estándar» de arriba pueden ser procesados por negligencia y perder su licencia ${ }^{19}$. Los de abajo tienen miedo de los proyectos legales de los políticos y cabilderos proaborto que obligarían a todos los ciudadanos a pagar los abortos $^{20}$. La conferencia episcopal de los EEUU (USCCB) acaba

17 Un seminario sobre «Libertad de religión o de creencias» (Viena, 9-10 de julio de 2009) reveló los nuevos desafíos para la libertad religiosa en Europa, cuando se recomendó extender la objeción de conciencia más allá del servicio militar, a todas las temáticas «humanas» como el aborto, la definición del matrimonio, la adopción de menores y la investigación con embriones humanos (Ombretta Fumagalli Carulli). El seminario fue celebrado en la reunión de la Organización para la Seguridad y la Cooperación en Europa, la cual actualmente sólo reconoce entre sus compromisos la objeción de conciencia relativa al servicio militar obligatorio.

18 El aborto es un buen ejemplo porque los que lo apoyan tienen prestigio, pero sus argumentos, a mi juicio, dejan mucho que desear.

Zenit, 2009-07-26: http://www.zenit.org/article-26553?l=german.

El proyecto de ley HR3200 requiere que los planes de salud privados y un plan público proporcione fondos para el aborto. También temen que los de arriba hagan que 
de amenazar con oponerse al plan de salud pública, promovido por los de arriba, porque las cinco versiones aprobadas en los comités asignan fondos federales a los abortos ${ }^{21}$. Para la gente de abajo resulta especialmente repugnante el aborto «eugenésico» (abortar a los que no gozarán de la «calidad de vida» requerida), que hace pensar en los programas de exterminación eugenésica de los nazis.

Parece mentira, pero ya se ha comenzado a hablar de una persecución religiosa en los EEUU.

\section{El velo de ignorancia}

Es claro que el aborto no es sino un ejemplo en toda una gama de conflictos humanísticos que tocan la libertad. Por tanto, es preciso tener claros criterios generales que definan lo que es y no es el abuso del poder. Necesitamos una teoría. No la tengo yo; como dije al principio, se la dejo a ustedes.

Al final, quisiera replantear esta cuestión metaética detrás del «velo de ignoracia», si me permiten usar la famosa metáfora de John Rawls. La propuso con la intención de garantizar la imparcialidad cuando hablamos de la justicia. En

el programa Social Medicaid cubra los abortos. El gobierno estadounidense ya ha destinado millones de dólares a Planned Parenthood, una organización que promueve y realiza abortos, y actualmente recibe la tercera parte de su presupuesto del gobierno; ver el Programa de Planificación Familiar Title X, bajo el que el gobierno de los Eevu destinó la suma récord \$288.3 millones de dólares en 2005 a la «planificación familiar»; 2009-07-24: http://www.zenit.org/article-26547?l=english.

21 Sin embargo, parece que el predominio educativo y mediático de arriba todavía no ha logrado convencer a todos los norteamericanos. Encuestas recientes muestran que tres de cuatro ciudadanos abogan por la protección legal para los profesionales que se niegan a participar en los abortos. Siete de cada diez se oponen (seis «enérgicamente») al uso de impuestos para financiar el aborto, y seis de diez desaprueban la reciente decisión del gobierno de dar dinero a los grupos que suministran abortos en el extranjero. Por supuesto, el problema moral no cambiaría si la estadística fuera al revés. Zenith, 2009-07-21: http://www.zenit.org/article-26519?l=english. 
su Theory of Justice (1971) nos dio este consejo: si queremos planificar la sociedad justa, que lo hagamos desde la «posición original», detrás de un velo de ignorancia. Es decir, debemos suponer que ignoramos cómo seremos en la sociedad que estamos proyectando: no sabemos si seremos ricos o pobres, listos o tontos, hombres o mujeres, blancos o negros, latinos o anglos, izquierdistas o derechistas, patrones o mano de obra, cristianos o ateos. Tal «neutralidad»-al parecer de Rawls- nos obligará a pensar «objetivamente».

Abordemos, pues, la cuestión metaética general del abuso del poder, pero antes pongámonos detrás del velo de ignorancia. Cuando decidimos si es lícito obligar a los disidentes a colaborar en el aborto, por ejemplo, finjamos ignorancia de si el aborto es lícito o no en el nivel primario. Y sobre todo, supongamos que no estamos sujetos a las usuales manipulaciones psicológicas que nos empujarían arriba. Pues detrás del velo de ignorancia ¡no sabemos si estamos arriba o abajo en la guerra de los humanismos!

Hay además otra consideración: somos profesores universitarios. ¿Cuál es nuestro papel en la guerra de los humanismos? ¡Sobre todo nosotros, los maestros «humanistas»! Nos quejamos de que se quiera eliminar las humanidades del programa o que se las considere como meras «auxiliares», que valen sólo como servicio a la administración de empresas, ingeniería, informática, medicina, psicología.

Pero cuando defendemos el humanismo, hay que preguntar: ¿qué humanismo? ¿Qué humanismo queremos enseñar a nuestros alumnos? La respuesta se relaciona estrechamente con la cuestión metaética acerca del derecho (o falta de derecho) de imponer un humanismo, una antropología, una ética. Nuestra enseñanza, ¿cómo afectará a las instituciones de la sociedad, a las comunidades débiles? ¿Cuál debe ser nuestra 
actitud hacia las tradiciones familiares de nuestros estudiantes? ¿Hay que respetar su conciencia? ¿Cómo hay que respetarla? ¿Cómo hemos de reconocer a los varios modos de ser humano? ¿Cómo situarnos detrás del velo de ignorancia y preservar el respeto -verdaderamente, no como en los EEUUsegún los altisonantes slogans orwelleanos de arriba, en los que «inclusión» significa marginalización, «diversidad» significa proscripción y «libertad» significa sometimiento?

Bibliografía

Bloch, E. (1968). Atheismus im Christentum. Zur Religion des Exodus und des Reichs. Gesamtausgabe (14).

Bloch, E. (1964). Himmelreich y Seligkeit. Geist der Utopie, Frankfurt am Main.

Bloch, E. (1957). Realutopie eines Reichs der Freiheit, christförmiges Topos, Heimat der Identität y Absolute Zukunft. En Das Princip Hoffung Frankfurt am Main.

Heidegger, M. (1976). Brief über den Humanismus. En Wegmarken. Gesamtausgabe, Frankfurt am Main, Vittorio Klostermann.

Rawls, J.E.K. (ed.). (2001) Justice as Fairness: a Restatement. Cambridge, Mass: Belknap.

Redmond, W. (2009). Lógica y mística/Progreso espiritual y progreso filosófico. Diánoia. 62 (44) 73-90.

Redmond, W. (2001). Arribismo intelectual y polarización religiosa en los Estados Unidos. Vertebración (UPAEP).

Redmond, W. (1988). Polarization in the Catholic Church. New Blackfriars, 926 (79), 187-196.

Wolin, R. (2006). Heidegger Made Kosher. The Nation, 20 de febrero.

Wilson, J. Q. (1993). The Moral Sense. Nueva York: Macmillan. 


\section{Resumen}

En este trabajo se pretende plantear una cuestión ética en torno a la pugna que se desarrolla entre dos tipos de humanismo en Estados Unidos, pero también en otras partes del mundo. Uno de esos humanismos está ganando. Lo que está en juego es la libertad. Me concentraré en el aspecto metaético de la cuestión, que revisa la imposición de normas éticas en general por parte del humanismo vencedor, como la permisividad del aborto o la eutanasia, sin respetar las objeciones de conciencia de quienes piensan distinto. Una forma de tratar de solucionar este tipo de problemas es el recurso al velo de la ignorancia, es decir, discutir las cuestiones metaéticas sin adoptar una posición previa en las discusiones.

Palabras clave: humanismo, ética, metaética, libertad.

\section{Absctract}

In this work I seek to point out an ethical question about the conflict between two humanisms of different kind, in the United States but also in other parts of the world. One of those humanisms is wining the fight. The core question is about the liberty. I will focus on the metaethical aspect of the problem, analyzing the imposition of general ethical norms from the wining humanism, such as permissiveness of abortion or euthanasia, regardless of the conscientious objections from those who think different. One way to solve this problem is the ignorance veil, that is to say, to discuss the metaethical questions without adopting any previous position.

Key words: humanism, ethics, metaethics, liberty. 
